\title{
Fatal hepatic necrosis in glandular fever
}

\author{
U. R. ALLEN AND B. H. BASS
}

From Good Hope Hospital, Sutton Coldfield

SYNOPSIS A young man of 24 developed glandular fever, became jaundiced, and died in hepatic coma. At necropsy massive necrosis of the liver was found, thus emphasizing that all grades of severity of liver damage may occur in infectious mononucleosis.

Glandular fever is essentially a benign disease, and it is for this reason that we think it worth while to record in detail the case history and pathology of a patient who died in hepatic coma.

\section{CASE HISTORY}

A. R., aged 24 years, was admitted to hospital on 18 September 1962 . Two weeks previously he had noticed severe headache and painful gums. One week later he developed a sore throat and experienced much malaise.

On examination he was flushed, ill, and febrile (temperature $102 \cdot 4^{\circ} \mathrm{F}$.). The fauces were injected and both tonsils enlarged, with a necrotic slough on the left. He had generalized lymph node enlargement most marked in the neck and the nodes were tender on palpation. The spleen was palpable as a firm swelling two fingerbreadths below the left costal margin; the liver edge could just be felt. He had slight neck stiffness but Kernig's sign was negative.

Glandular fever was diagnosed and confirmed by haematological investigation. The total white cell count was $11,000 /$ c.mm. (neutrophils $40 \%$, lymphocytes $49 \%$, monocytes $11 \%$ ), Hb 15 g. $/ 100$ ml., platelets $160,000 /$ c.mm., and a peripheral blood film showed numerous atypical mononuclear cells suggestive of glandular fever. The Paul Bunnel test after adsorption with guinea-pig kidney was originally $1: 64$ and this rose to a titre of $1: 128$ after one week.

Because of increasing headache and meningism a

Received for publication 15 February 1963. lumbar puncture was performed. The cerebrospinal fluid was under increased pressure and had a raised cell count of $65 / \mathrm{c} . \mathrm{mm}$., all lymphocytes; the protein content was $45 \mathrm{mg} . \%$.

On the third day after admission he was noted to be jaundiced; his urine had contained urobilinogen on the day of admission.

Liver function tests on admission and subsequently are shown in Table I.

On 25 September he had a brisk epistaxis which required packing of the nasal cavity to control it. The prothrombin content of the blood was then $52 \%$ and he was immediately given $\mathbf{4 0} \mathrm{mg}$. of vitamin $\mathrm{K}$ intravenously.

The bleeding ceased, but on the following day a flapping tremor of the hands was noted and foetor hepaticus was detected.

He was treated for liver failure in the usual way, i.e., by oral neomycin, and by magnesium sulphate orally and as an enema. A low-protein, high-carbohydrate diet was given and corticosteroids in high dosage were commenced. Despite this régime he deteriorated rapidly and went into coma, dying on 26 September. A necropsy was performed.

\section{REPORT OF NECROPSY}

Necropsy was performed 16 hours after death.

The body was that of a moderately jaundiced young man with numerous purpuric spots and petechiae in the skin. The liver was grossly abnormal; it weighed $2,250 \mathrm{~g}$. and was slightly

TABLE I

RESULTS OF LIVER FUNCTION TESTS

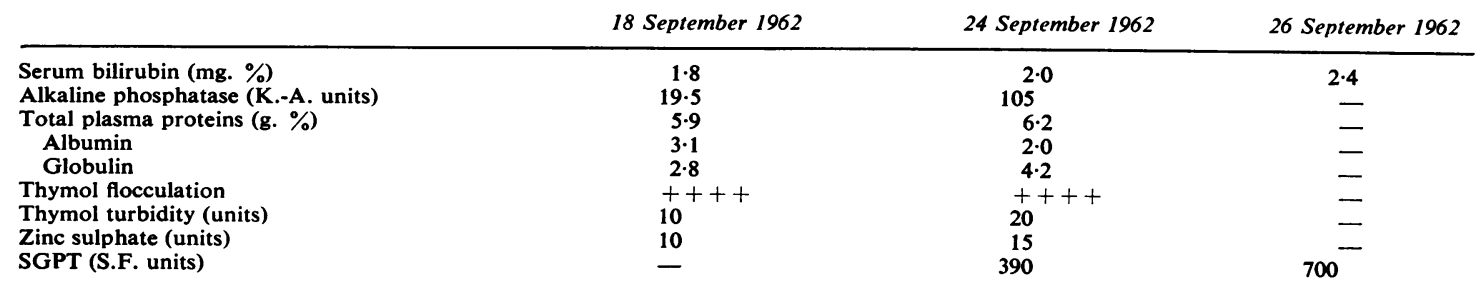


enlarged, swollen and soft; the surface was smooth and of a variable red and yellow colour but not haemorrhagic; on section the cut surface was uniformly a deep golden yellow, relatively avascular and the parenchyma swollen; the gall bladder contained a little yellow mucoid bile and the extrahepatic bile ducts were not obstructed.

The spleen was thrice its normal size, weighing 450 g., and was dark red with a smooth, tense capsule; on section the surface was soft and of homogenous appearance, no Malpighian bodies being visible.

The lymph nodes in the neck, mesentery, porta hepatis, para-aortic chain, groins, and axillae were enlarged up to $3 \mathrm{~cm}$. in length, firm and discrete; on section they presented a uniform greyish white surface; two of the larger mesenteric nodes were necrotic. The mediastinal glands appeared less affected.

The alimentary system was normal apart from ulceration of the tonsils and pharynx.

The heart weighed $280 \mathrm{~g}$. and was somewhat dilated and the myocardium paler than usual; the

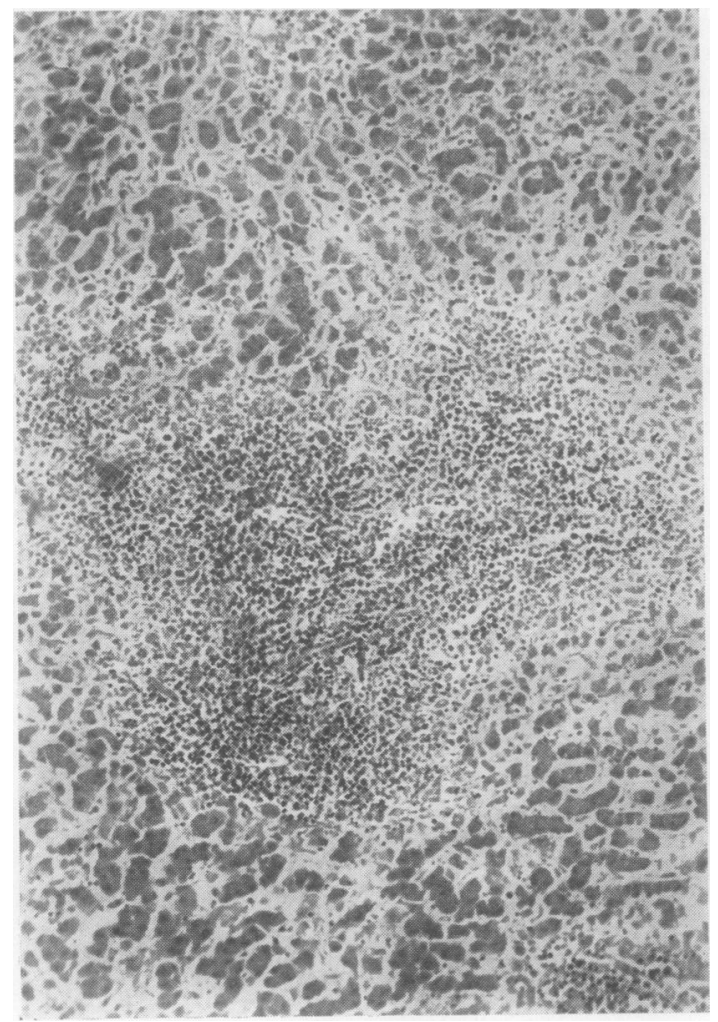

FIG. 1. Massive hepatic necrosis (haematoxylin and $\operatorname{eosin} \times 100$ ). valves and coronary arteries were normal. The lungs showed terminal oedema.

The kidneys were jaundiced but showed no other 으 macroscopic abnormality apart from slight blurring of the corticomedullary pattern.

The bone marrow was of normal distribution and colour.

The brain was not under tension and the meninges and sulci appeared normal; on section small congested cerebral vessels were seen, but no petechiae. के

The remaining organs showed no abnormality.

\section{HISTOLOGY}

The most striking feature of this case was the wide- $\vec{\sigma}$ spread distribution of pathological lesions and the ubiquity of foci of abnormal mononuclear cells; these cells have been described by Custer and Smith (1948) and by Sharp (1950) and can be recognized in sections stained by haemotoxylin and eosin as relatively large round cells 10 to $15 \mu$ in diameter, with plentiful cytoplasm and oval, round, or indented

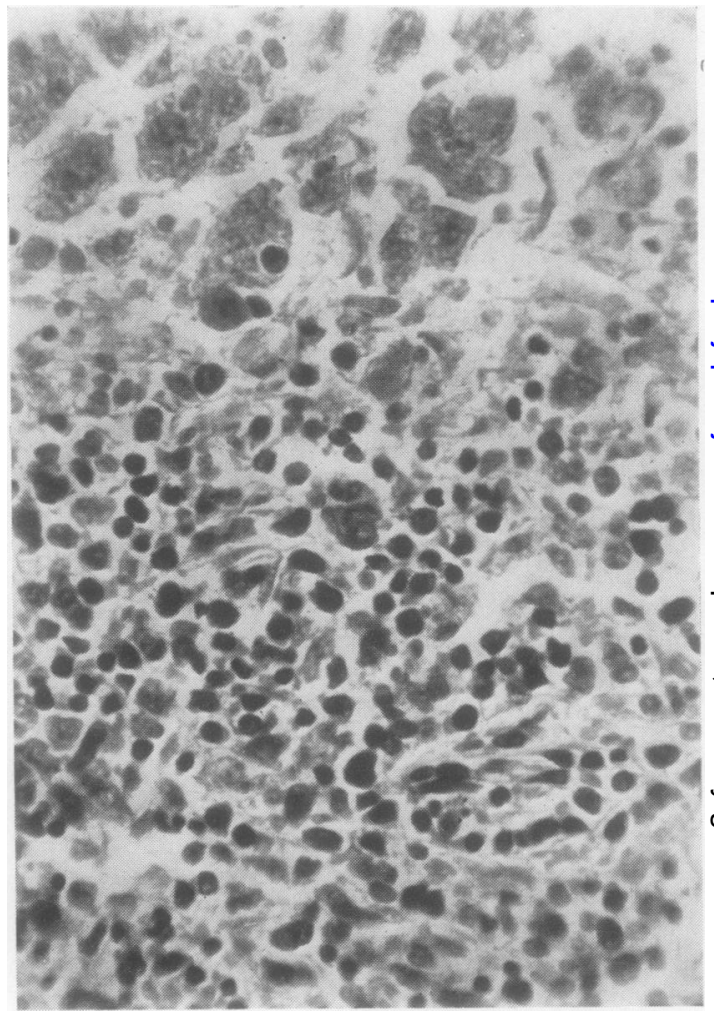

FIG. 2. Abnormal mononuclear cells and lymphocytes in the portal tract (haematoxylin and eosin $\times 450$ ). 


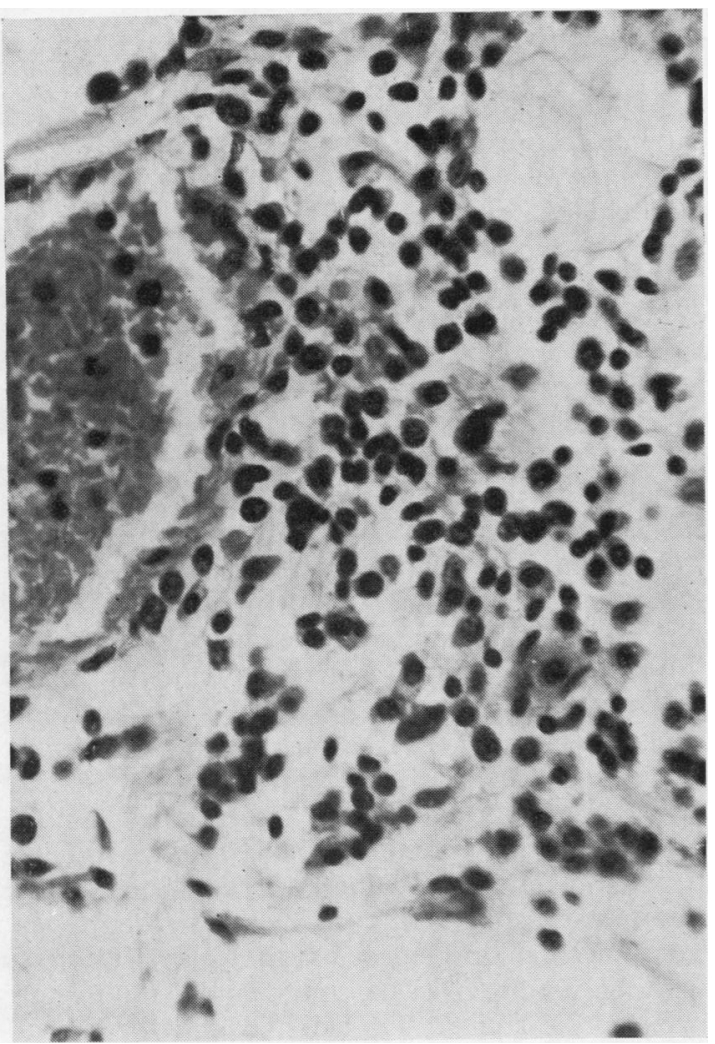

FIG. 3. Lymph node: abnormal mononuclear cells in efferent sinus (haematoxylin and eosin $\times 450$ ).

nuclei which exhibit a very well-defined chromatin pattern and are sharply delineated.

There was massive necrosis throughout the liver (Fig. 1), in some areas whole lobules being degenerate, in others the more central hepatic cells showing the greater disintegration. In the portal tracts there were bands of abnormal mononuclear cells, lymphocytes, and a few neutrophil polymorphs (Fig. 2). Many of the hepatic cells contained fine deposits of bile but there was no dilatation or proliferation of bile ducts as is found in obstructive jaundice.

There was a thinning of the capsule of the spleen which was invaded by abnormal mononuclear cells. A generalized cellular hyperplasia of the cords of Billroth obscured the distinction between red and white pulp, and Malpighian bodies were small and ill-defined; abnormal mononuclear cells could be seen in the sinuses.

Sections of the lymph nodes stained for reticulin demonstrated that the normal underlying architecture was preserved; there was, however, considerable pleomorphism of the reticulum cells of the medullary cords; this was more marked in some

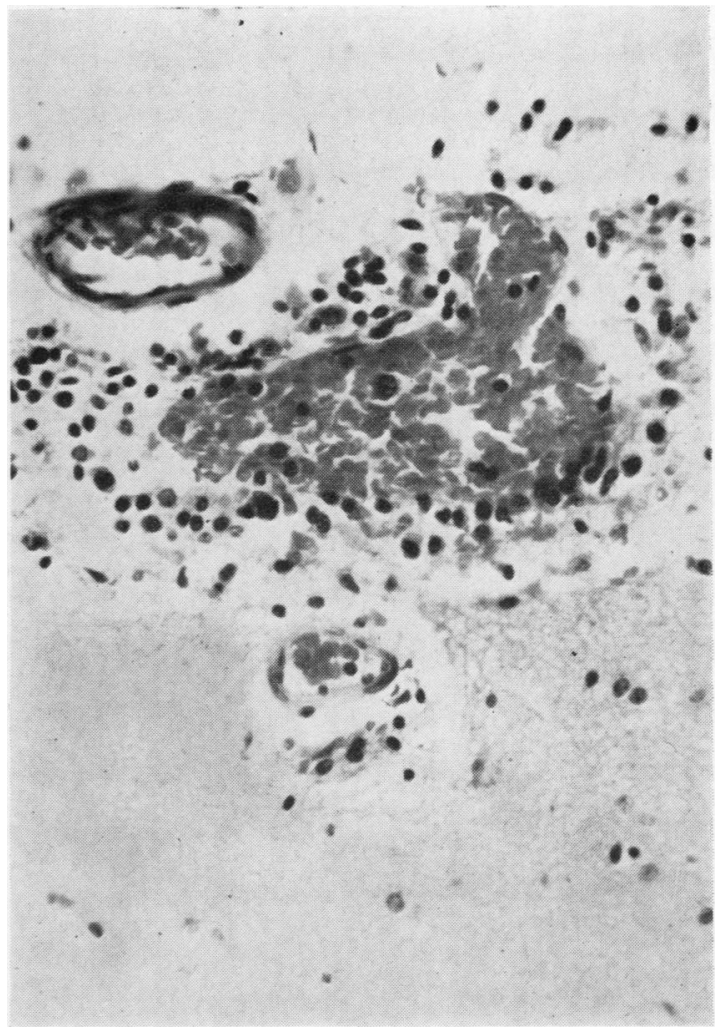

FIG. 4. Meninges: perivascular focus of abnormal mononuclear cells (haematoxylin and eosin $\times 250$ ).

lymph nodes, e.g., mesenteric, than others, e.g., cervical; abnormal mononuclear cells were prominent and could be seen in the efferent sinuses (Fig. 3).

The meninges showed perivascular foci of abnormal mononuclear cells (Fig. 4). Similar foci were seen in the myocardium and adrenals.

The kidneys (Fig. 5) exhibited marked tubular degeneration with granular casts but the glomeruli appeared normal; there were scattered intertubular collections of abnormal mononuclear cells.

The bone marrow was of normal pattern and range of cells with an apparent increase in megakaryocytes.

The lungs showed pulmonary oedema.

\section{DISCUSSION}

The diagnosis of glandular fever in this case was made on the characteristic blood picture and confirmed serologically. The Paul Bunnell reaction after adsorption rose to a titre of $1: 128$, and this must be regarded as diagnostic of glandular fever (Davidsohn, Stern, and Kashiwagi (1951); Carpenter, Kahler, 


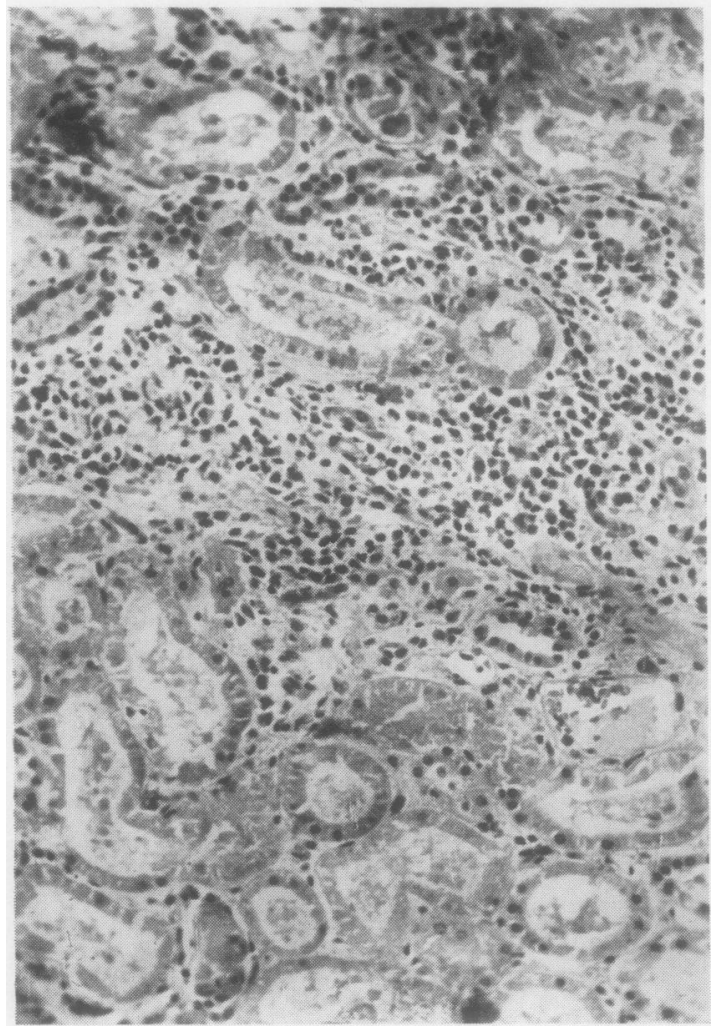

FIG. 5. Renal tubular degeneration: collections of abnormal mononuclear cells between tubules (haematoxylin and eosin $\times 150$ ).

and Reilly (1950). Because of the severity of the disease, we also considered the possibility of an acute leukaemia. The blood picture was not in accord with this but histological sections of parenchymal organs may present a picture not unlike that of leukaemic infiltration. This feature has been mentioned by several authors in previous reviews (Custer and Smith, 1948; Shinton and Hawkins, 1956).

Our patient worked as an artificial inseminator of cows and in view of this occupation Weil's disease was also considered. Agglutination titres against $L$. icterohaemorrhagica were negative in the third week, and the clinical course of the disease was not that of leptospirosis in that he did not show the pattern of renal failure, and apart from the epistaxis there were no haemorrhages, except terminally.

On searching the literature it is apparent that hepatic failure is an exceedingly rare cause of death in glandular fever. This contrasts with the very common occurrence of liver involvement in the course of the disease. Rosalki, Gwyn Jones, and 0 Verney (1960) investigated 23 patients of whom $\overrightarrow{\vec{\sigma}}$ only two had clinical hepatitis. In all these $\frac{}{\cdot}$ patients the serum glutamic pyruvic transaminase $\overrightarrow{\vec{D}}$ (SGPT) level was raised in no less than $83 \%$ and the colloidal gold reaction was positive in $85 \%$. 당 Similar findings were described by Mason and Adams (1958). Using the bromsulphthalein test these $\vec{\Phi}$ workers found abnormal retention of dye in $80 \% \frac{\Omega}{0}$ of 100 unjaundiced glandular fever patients.

ต

Nelson and Darragh (1956) describe three phases $\overrightarrow{0}$ of liver involvement in glandular fever in declining $\overrightarrow{.}$ order of commonness. All were detected by per- $\omega$ cutaneous liver biopsy as none of their 22 patients died. 1 Portal exudates consisting almost entirely? of mononuclear cells; 2 invasion of sinusoids by $\bar{\sigma}$ mononuclear cells; 3 areas of scattered focal $\dot{\omega}$ necrosis filled with mononuclear cells.

We consider that our patient demonstrated a 0 fourth phase, that of massive hepatic necrosis, which must be of extreme rarity; only one similar

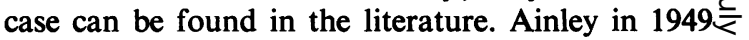
described a young man of 23 who developed jaundice $\vec{\theta}$ three days after the beginning of his illness, which was heralded by fever and pain in the back; the jaundice deepened and nose bleeds and a skin rash developed; he rapidly deteriorated and died 10 days after the onset of symptoms. The spleen and lymph nodes were enlarged clinically, blood counts were char- $\frac{0}{\circ}$ acteristic, and the Paul Bunnell test was positive at $\varrho$ a titre of $1 / 512$; the urine contained albumin and bile; $\overrightarrow{\text { 을 }}$ the van den Bergh reaction was reported as $4 \mathrm{mg}$. \%, prothrombin index $20 \%$, total serum proteins? $3.75 \mathrm{~g} . \%$. At necropsy the immediate cause of death was shown to be gastrointestinal haemorrhage; the liver weighed $2,130 \mathrm{~g}$. and was pale yellowish-brown:throughout, soft, and on section the lobular pattern 3 . was indistinct; the biliary system and blood vessels $\delta$ were normal. The spleen weighed $900 \mathrm{~g}$. and was $₹$ bright red and swollen on section and no Mal-o pighian bodies could be made out; lymph nodes were enlarged and there was pulmonary oedema. The histology of the liver was very similar to that of the case we have described, namely, a very extensive centrilobular necrosis, only a few liver cells around 0 the portal tracts surviving; there was considerable infiltration of the portal tracts by abnormal mono-nuclear cells, lymphocytes, and a few polymorphs Bile ducts and blood vessels were normal. Wide--क spread foci of abnormal mononuclear cells were? found in the myocardium and endocardium, lungs, 0 kidneys, and meninges; the bone marrow showed no specific cellular proliferation or infiltration $\overparen{\curvearrowright}$ Ainley stresses the similarity of the histologica $\frac{1}{0}$ picture of the liver to that seen in infective hepatitiso in the acute phase and remarks that the exact 
relationship between the two diseases has still to be defined.

Another fatal case of glandular fever with jaundice, a young man of 24, was described by Marshall and Millingen in 1952. Four weeks after the onset of symptoms he became icteric and died within a week; renal failure was, however, the most conspicuous feature in this case, the blood urea rising to $300 \mathrm{mg} . \%$ and the urine being laden with albumin and granular casts throughout the illness. Typical glandular fever cells were present in the blood and the Paul Bunnell test was positive, adsorbed, at a titre of $1 / 256$. At necropsy the liver was slightly enlarged and showed a pinkish-yellow mottling; microscopically there was moderate perilobular fibrosis and infiltration portally and pericellularly by lymphocytes, atypical mononuclear cells, and a few giant cells. Areas of liver necrosis were present though not extensive, but the authors remarked that the clinical picture [of liver failure] was 'more severe than the actual hepatic damage would suggest'; they believed that renal failure was the dominating factor and speculated on the significance of the tubular degeneration and cellular infiltration which was found in their case, as in ours. Lou Fang Ts'en (1959) in a brief description of a Chinese dying of glandular fever, observed 'scattered haemorrhages, degeneration, and necrosis of parenchymal cells and infiltration of mononuclears in the liver, kidney, and adrenal cortex'.

The histological findings in the liver at necropsy in non-jaundiced patients dying of glandular fever are of interest. The most comprehensive review of the pathology of infectious mononucleosis is that by Custer and Smith (1948). In nine fatal cases they found marked lymphocytic infiltration in the hepatic periportal connective tissue varying in degree and approaching that of lymphatic leukaemia; necrosis of liver parenchyma, however, was not observed in their series. Sharp (1950) also reports fully a fatal case of a man of 22 who died suddenly of a pneumothorax; again, though there was no jaundice, the portal tracts were infiltrated by abnormal mononuclear cells, lymphocytes, and polymorphs and there was slight generalized cloudy swelling of the liver cells but no evidence of biliary obstruction. Shinton and Hawkins in 1956 recorded a fatal case of glandular fever in a boy of 17; he was not jaundiced but at necropsy 'narrow bands of lymphoid tissue' could be seen in the liver and microscopically these were identified as atypical mononuclear cells.

Ziegler (1944) described the histology of the liver in a patient, not icteric, who died from haemorrhage secondary to rupture of the spleen in the fourth week of glandular fever; there was cellular infiltration, chiefly but not wholly perilobular, by mononuclear cells, swollen Küpffer cells, and occasional polymorphs, eosinophils, and lymphocytes. The hepatic parenchyma showed destruction and disappearance of the liver cells in and around these foci. Ziegler was one of the first to emphasize that the basic underlying pathology is a diffuse focal hepatitis only varying in degree in different cases. The patient described in this paper had the misfortune to fall at the extreme end of the scale of severity of liver failure and hepatic disorganization.

We wish to thank Mr. A. D. Randle, F.I.M.L.T. for technical assistance and Mr. S. Gaunt, F.I.M.L.T. of The Queen Elizabeth Hospital, Birmingham, for the photomicrographs.

\section{REFERENCES}

Ainley, N. J. (1949). Ulster med. J., 18, 219.

Carpenter, G., Kahler, J., and Reilly, E. B. (1950). Amer. J. med. Sci., 220, 195.

Custer, R. P., and Smith, F. B. (1948). Blood, 3, 830.

Davidsohn, I., Stern, K., and Kashiwagi, C. (1951). Amer. J. clin. Path., 21, 1101.

Lou Fang-Ts'en (1959). Chin. med. J., 79, 175.

Marshall, S., and Millingen, K. S. (1952). Brit. med. J., 1, 1325.

Mason, W. R. Jr., and Adams, E. K. (1958). Amer. J. med. Sci., 236, 447.

Nelson, R. S., and Darragh, J. H. (1956). Amer. J. Med., 21, 26.

Rosalki, S. B., Gwyn Jones, T., and Verney, A. F. (1960). Brit. med. J., 1, 929.

Sharp, M. E. (1950). J. Path. Bact., 62, 175.

Shinton, N. K., and Hawkins, C. F. (1956). Lancet, 2, 708.

Ziegler, E. E. (1944). Arch. Path., 37, 196. 